\title{
The Effect of Water Concentration in Ethyl Alcohol on the Environmentally Assisted Embrittlement of Austempered Ductile Irons
}

\author{
Petar Janjatovic $^{1}{ }^{1}$, Olivera Eric Cekic ${ }^{2}$, Leposava Sidjanin ${ }^{1}$, Sebastian Balos $\left.{ }^{1}{ }^{(}\right)$, Miroslav Dramicanin ${ }^{1}{ }^{\circledR}$, \\ Jasmina Grbovic Novakovic ${ }^{3}$ and Dragan Rajnovic ${ }^{1, *(D)}$
}

1 Department of Production Engineering, Faculty of Technical Science, University of Novi Sad, Novi Sad, Trg Dositeja Obradovica 6, 21000 Novi Sad, Serbia; janjatovic@uns.ac.rs (P.J.); lepas@uns.ac.rs (L.S.); sebab@uns.ac.rs (S.B.); dramicanin@uns.ac.rs (M.D.)

2 Department of General Engineering Education, Faculty of Mechanical and Civil Engineering in Kraljevo, University of Kragujevac, Dositejeva 19, 36000 Kraljevo, Serbia; eric.o@mfkv.kg.ac.rs

3 Center of Excellence for Hydrogen and Renewable Energy, "Vinča" Institute of Nuclear Sciences, National Institute of Republic of Serbia, University of Belgrade, P.O. Box 522, 11000 Belgrade, Serbia; jasnag@vinca.rs

* Correspondence: draganr@uns.ac.rs

check for updates

Citation: Janjatovic, P.; Eric Cekic, O.; Sidjanin, L.; Balos, S.; Dramicanin, M.; Grbovic Novakovic, J.; Rajnovic, D. The Effect of Water Concentration in Ethyl Alcohol on the Environmentally Assisted Embrittlement of Austempered Ductile Irons. Metals 2021, 11, 94. https://doi.org/ $10.3390 /$ met11010094

Received: 4 December 2020 Accepted: 29 December 2020 Published: 5 January 2021

Publisher's Note: MDPI stays neutral with regard to jurisdictional clai$\mathrm{ms}$ in published maps and institutional affiliations.

Copyright: $\odot 2021$ by the authors. Licensee MDPI, Basel, Switzerland. This article is an open access article distributed under the terms and conditions of the Creative Commons Attribution (CC BY) license (https:// creativecommons.org/licenses/by/ $4.0 /)$.

\begin{abstract}
Austempered ductile iron (ADI) is an advanced cast iron material that has a broad field of application and, among others, it is used in contact and for conveyance of fluids. However, it is noticed that in contact with some fluids, especially water, ADI material becomes brittle. The most significant decrease is established for the elongation. However, the influence of water and the cause of this phenomenon is still not fully understood. For that reason, in this paper, the influence of different water concentrations in ethyl alcohol on the mechanical properties of ADI materials was studied. The test was performed on two different types of ADI materials in $0.2,4,10$, and 100 vol.\% water concentration environments, and in dry condition. It was found that even the smallest concentration of water $(0.2 \mathrm{vol} . \%)$ causes formation of the embrittled zone at fracture surface. However, not all mechanical properties were affected equally and not all water concentrations have been critical. The highest deterioration was established in the elongation, followed by the ultimate tensile strength, while the proof strength was affected least.
\end{abstract}

Keywords: austempered ductile iron; water embrittlement; mechanical properties; fracture behavior

\section{Introduction}

The development of the automotive, agricultural, railroad, mining, and other heavy industry sectors showed the continuous need for improving existing materials or using newly developed ones [1]. Research gravitates towards the achievement of the best possible mechanical properties while saving the cost and weight of the final product, with a number of benefits by itself. The material that meets many of the above requirements is cast iron [2]. Cast irons have several advantages compared with cast steel such as lower volume shrinkage during solidification and $20-40 \%$ lower manufacturing cost, better vibration damping, and wear resistance [3]. To improve the existing properties of cast iron, specifically ductile iron, thermal treatment is applied in order to obtain ausferritic microstructure, and thus increase mechanical properties [4]. The ausferrite is a mixture of ausferritic ferrite and carbon-enriched retained austenite [5-7]. This new material is known as the austempered ductile iron (ADI). The ADI has an outstanding combination of high strength, toughness, and ductility, as well as good fatigue resistance and wear [8-13]. The ADI also possesses excellent castability, with lower manufacturing cost (for $20 \%$ ) and lower density (around 10\%) than that of cast steel [14,15]. Its mechanical properties and relatively low cost render ADI materials an attractive replacement for the wrought and 
casting steels [16]. The ADI can be produced with a wide array of ultimate tensile strengths (UTS), ranging from $850 \mathrm{MPa}$ to $1600 \mathrm{MPa}$ and elongations between 10 and close to $0 \%$, respectively [17].

One significant disadvantage of the ADI is that it suffers observable embrittlement when its surface is in contact with liquids [17-23]. Shibutani et al., in their pioneering study [23], first reported phenomenon of water influence on austempered ductile irons (ADI), and reported that tensile strengths of about $1000 \mathrm{MPa}$ and elongation of $8 \%$ obtained in dry testing decreased to about $700 \mathrm{MPa}$ and $1.5 \%$ in the presence of water. Martínez et al. [20] obtained similar results and confirmed the existence of the embrittlement. However, the samples were tested also in mineral oil and isopropyl alcohol. These environments, while causing less embrittlement than water, still produced significant reductions of mechanical properties. Tensile strengths were reduced by $23-30 \%$ in water, $15 \%$ in $99 \%$ isopropyl alcohol, and 1-10\% in SAE 30 mineral lubricant oil. More critically, there was a reduction of the elongation by $73-83 \%$ in water, $67 \%$ in $99 \%$ isopropyl alcohol, and $29-47 \%$ in SAE 30 mineral lubricant oil [20]. Further research $[17,19,21]$ reported that after drying, the specimens reverted to their previous tensile properties. On the other hand, impact properties were not affected in water environment $[17,19,21]$. This indicates that the environmentally affected embrittlement does not appear at high strain rates. Furthermore, the effect shows no dependency on the time of exposition to water $[19,21]$.

There are several explanations for the embrittlement effect. One of them is hydrogen embrittlement $[19,20,24,25]$. In steels, hydrogen embrittlement is most pronounced when ferrite or martensite is present and at slow strain rates where diffusion process is intensified [26,27]. On the contrary, in ADI materials, liquid embrittlement process is occurring very fast, and unlike steels, it is not pronounced in ferritic microstructure $[19,28]$. Masud et al. [21] proposed that the embrittlement process is not an electrochemical phenomenon and hydrogen atoms are not causing the embrittlement. They suggested a different model, which implies chemisorption. Contrarily, our previous research [29] showed that only the water and hydrogen gas considerably decreased mechanical properties, that is, caused the embrittlement, while small (helium) or large gaseous atoms (argon) have no impact. Furthermore, the fracture surface analysis suggested that the embrittled zone morphology near the specimen surface shares undeniable similarities to the fatigue fracture surface containing common striation lines. This indicates that cyclic local-chemisorption, microembrittlement, and local-fracture play a key role in forming the brittle zone and thus brittle behavior of the ADI material [29]. Chemisorption weakens the atomic bonds in the metal and, in the presence of adequate stress, initiates a crack that becomes unstable under critical strain and grows rapidly. On the other hand, Caballero et al. [22] reported that the water is a substance which embrittles ADI, not hydrogen per se, as previous researchers reported in their studies.

The aim of this work is to study the embrittlement behavior of two types of ADI materials in different water concentrations. More specifically, the aim is to find the relationship between the mechanical properties and the concentration of dissolved water in ethyl alcohol.

\section{Materials and Methods}

\subsection{Materials}

The cast irons were produced in Y blocks having the bottom and upper widths of 25 and $54 \mathrm{~mm}$, respectively, the height of $150 \mathrm{~mm}$ and a length of $200 \mathrm{~mm}$. The spheroidization was achieved by adding 2.2 wt.\% FeSiMg5 alloy (containing $5 \mathrm{wt}$ \% of $\mathrm{Mg}$ ), and postinoculation with FeSi (containing $75 \mathrm{wt} . \% \mathrm{Si}$ ). The chemical composition of as-cast ductile iron is shown in Table 1.

Microstructures before and after etching are shown in Figure 1. The graphite spheroidization (roundness) was more than $90 \%$, the average graphite volume fraction was $12 \pm 1.6 \%$, nodule count distribution was from 125 to $175 \mathrm{~mm}^{-2}$, and nodule size was from 15 to 
$30 \mu \mathrm{m}$, which is shown in Figure 1a. Etched microstructure uncovered predominantly ferritic metal matrix with $10 \%$ of pearlite, as depicted in Figure $1 \mathrm{~b}$.

Table 1. The chemical composition of ductile iron.

\begin{tabular}{ccccccccc}
\hline $\mathbf{C}$ & $\mathbf{S i}$ & $\mathbf{M n}$ & $\mathbf{N i}$ & $\mathbf{C r}$ & $\mathbf{M g}$ & $\mathbf{P}$ & $\mathbf{S}$ & $\mathbf{F e}$ \\
\hline 3.5 & 2.5 & 0.35 & 0.05 & 0.06 & 0.031 & 0.018 & 0.015 & balance \\
\hline
\end{tabular}

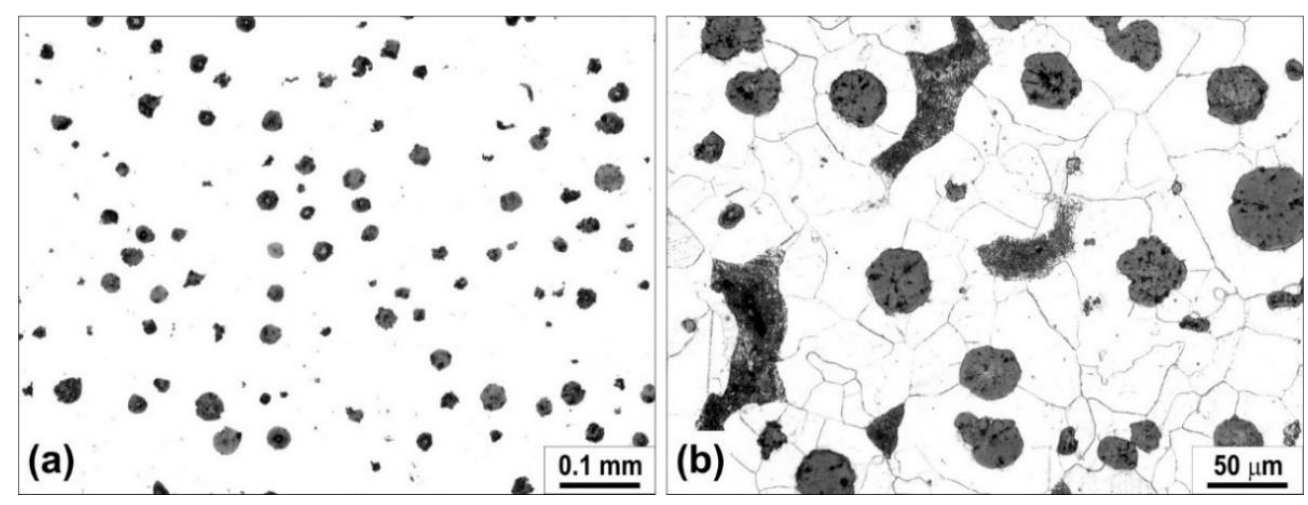

Figure 1. Microstructure of as-cast ductile iron: (a) Polished; (b) etched.

For each intended test, a set of ductile iron specimens was heat-treated to produce two types of ADI materials. Ductile cast iron specimens were austenitized at $900{ }^{\circ} \mathrm{C}$ for one hour in the furnace with a protective argon atmosphere. After that, specimens were rapidly transferred to salt bath and quenched at two different temperatures 400 and $300{ }^{\circ} \mathrm{C}$ for one hour, to produce materials designated ADI 904 and ADI 903, respectively. After heat treatment, specimens were cooled in the air to room temperature.

Time of austempering was selected on the basis of optimizing the maximum retained austenite volume fraction. On the other hand, different austempering temperatures affect the microstructure morphology. The resulting microstructures of ADI 904 and ADI 903 are shown in Figure 2. In both samples, the microstructure is fully ausferritic, consisting of a mixture of ausferritic ferrite and carbon enriched retained austenite, but with different morphology. In ADI 904, a plate-like morphology with $29.6 \pm 2.1 \%$ volume fraction of the retained austenite (Figure 2a) was obtained, unlike ADI 903 where needle-like morphology with $14.4 \pm 1.8 \%$ volume fraction of the retained austenite (Figure $2 b$ ).
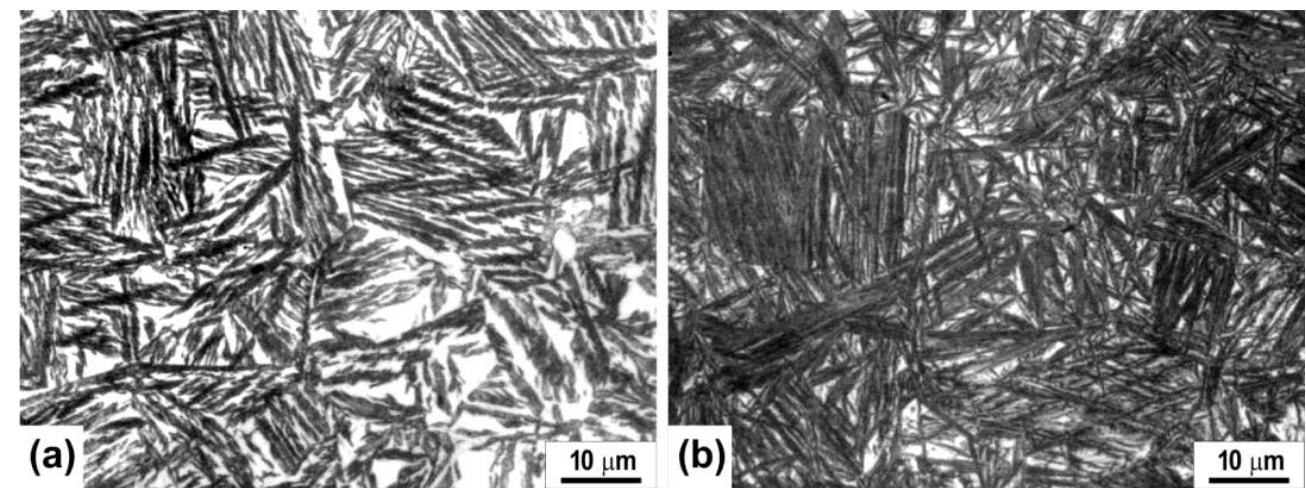

Figure 2. Microstructure of austempered ductile iron (ADI) materials: (a) ADI 904; (b) ADI 903.

The mechanical properties were also affected by the austempering temperatures: The higher austempering temperature influenced a higher ductility and lower strength, while the lower austempering temperature provided lower ductility and higher strength. The me- 
chanical properties $(0.2 \%$ proof strength $-\mathrm{PS}$; ultimate tensile strength—UTS, elongationA and hardness-HV10) of ductile cast iron, ADI 904, and ADI 903 are given in Table 2.

Table 2. The mechanical properties of ductile cast iron, ADI 904, and ADI 903.

\begin{tabular}{ccccc}
\hline Material & $\begin{array}{c}\text { Proof Strength } \\
(\mathbf{P S}) \mathbf{R}_{\mathbf{p 0 . 2}} \mathbf{( M P a )}\end{array}$ & $\begin{array}{c}\text { Ultimate Tensile Strength } \\
\text { (UTS) } \mathbf{R}_{\mathbf{m}} \mathbf{( M P a )}\end{array}$ & $\begin{array}{c}\text { Elongation } \\
\text { A (\%) }\end{array}$ & $\begin{array}{c}\text { Hardness } \\
\text { HV10 }\end{array}$ \\
\hline Ductile iron & 318 & 456 & 19.1 & 150 \\
\hline ADI 904 & 722 & 959 & 11.5 & 284 \\
\hline ADI 903 & 1244 & 1450 & 4.5 & 425 \\
\hline
\end{tabular}

\subsection{Methods}

To assess the behavior of ADI materials in different environments, tensile testing was performed. The tensile testing system consisted of a tensile testing machine ZDM 5/91 (WPM, Leipzig, Germany) equipped with S-type measuring tension force sensor and linear variable differential transformer LVDT inductive sensor (HBM, Darmstadt, Germany). The sensors were connected to a PC by a Spider 8 (HBM, Darmstadt, Germany) acquisition device. Round tensile test specimens had the diameter of $6 \mathrm{~mm}$ and a gauge length of $30 \mathrm{~mm}$ with enlarged M10 threaded gripping ends. Tensile testing specimens were machined from the bottom part of the Y-block. The tensile testing was done according to ISO 6892-1.

The specimens were tested in distilled water and various mixtures of water and ethylalcohol. The following mixtures consisted of $0.2,4$, and 10 vol. $\%$ of distilled water in ethyl-alcohol $\left(\mathrm{C}_{2} \mathrm{H}_{5} \mathrm{OH}\right)$, were made. The mixtures were designated $0.2 \% \mathrm{~W}, 4 \% \mathrm{~W}$, and $10 \% \mathrm{~W}$, respectively. Designation W was used for pure water (100 vol.\%), and D for dry testing condition. Three specimens were tested for each testing condition (dry and different water concentrations environments).

Tensile specimens in water (wet) condition were tested using an assembly that consisted of a polymer (Polyethylene terephthalate-PET) tube with thread in the end and a bottle cap. The sample holder passed through the bottle cap and they were insulated by the tape. The PET tube was fully surrounding the overall length of the sample. The tube was filled with fluid, then the upper holder of the specimen was placed. Specimen tensile testing setup is shown in Figure 3. The duration of the contact of the specimen with the testing fluid was one minute.
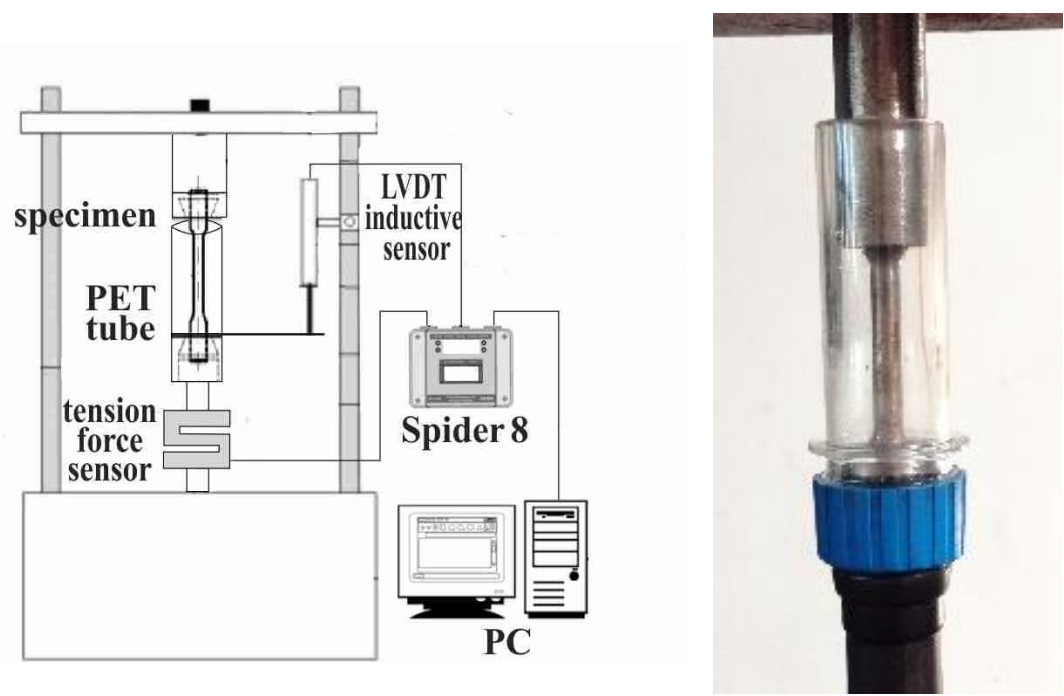

Figure 3. Tensile testing setup and detail of sample and Polyethylene terephthalate (PET) tube. 
Three Vickers hardness measurements were done for each sample according to ISO 6507. The testing machine was an HPO 250 (WPM, Leipzig, Germany), with a test load of $98.07 \mathrm{~N}$ (10 kgf) and a dwell time of $15 \mathrm{~s}$.

The common metallographic preparation was conducted by grinding using $\mathrm{SiC}$ abrasive papers (P150 to P2500 grit), followed by polishing by using diamond suspensions $(6,3$, 1 , and $0.25 \mu \mathrm{m})$ and etching by $2 \%$ nital $\left(2 \%\right.$ nitric acid- $\mathrm{HNO}_{3}$ in alcohol). Microstructures were examined by Orthoplan (Leitz, Wetzlar, Germany) light microscope. Furthermore, fractured surfaces were analyzed by a scanning electron microscope (SEM) JEOL JSM 6460LV (JEOL, Tokyo, Japan) operated at $25 \mathrm{kV}$.

The relationship between the amount (\% in volume) of retained austenite, ausferritic ferrite, and graphite in microstructures was quantified by image analysis. The reported values are the average of at least five fields of view on each sample.

\section{Results}

\subsection{Mechanical Testing Results}

The results of tensile properties of ADI 904 and ADI 903 in dry and different water environments are given in Figures 4-7 and Tables 3-5. In addition to the mean values of tensile properties, Tables $3-5$ show the standard deviation and the P parameter.

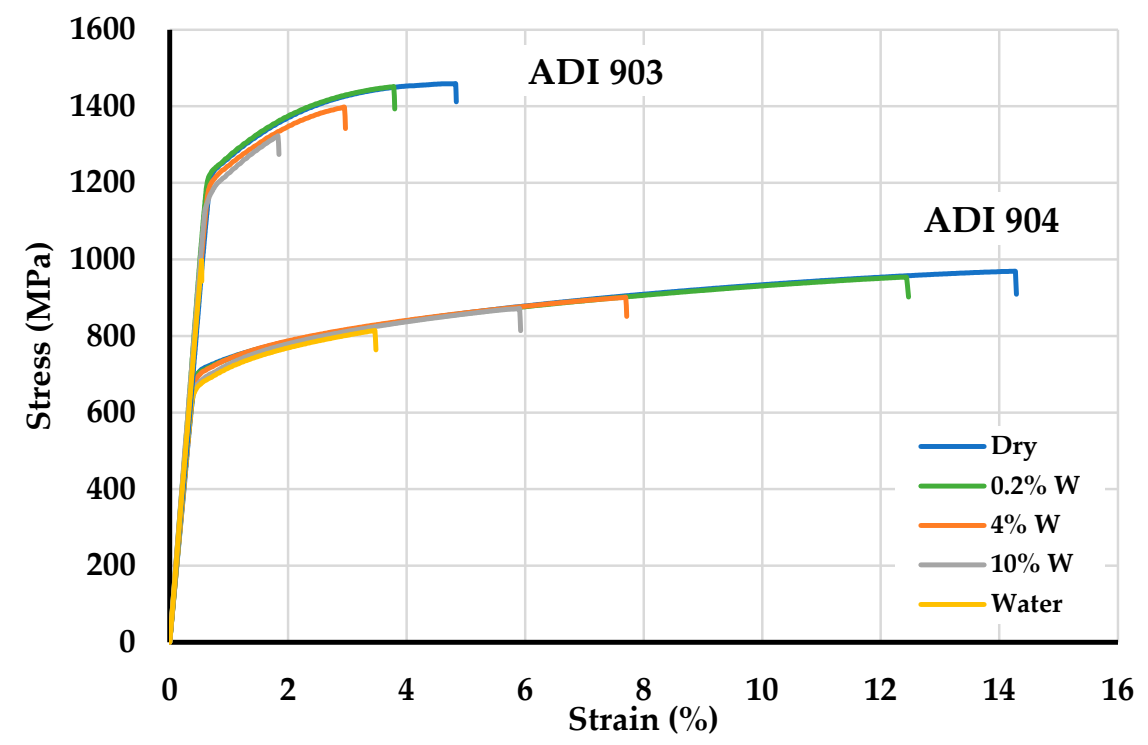

Figure 4. Representative stress-strain curves of ADI 904 and ADI 903 in various environments.

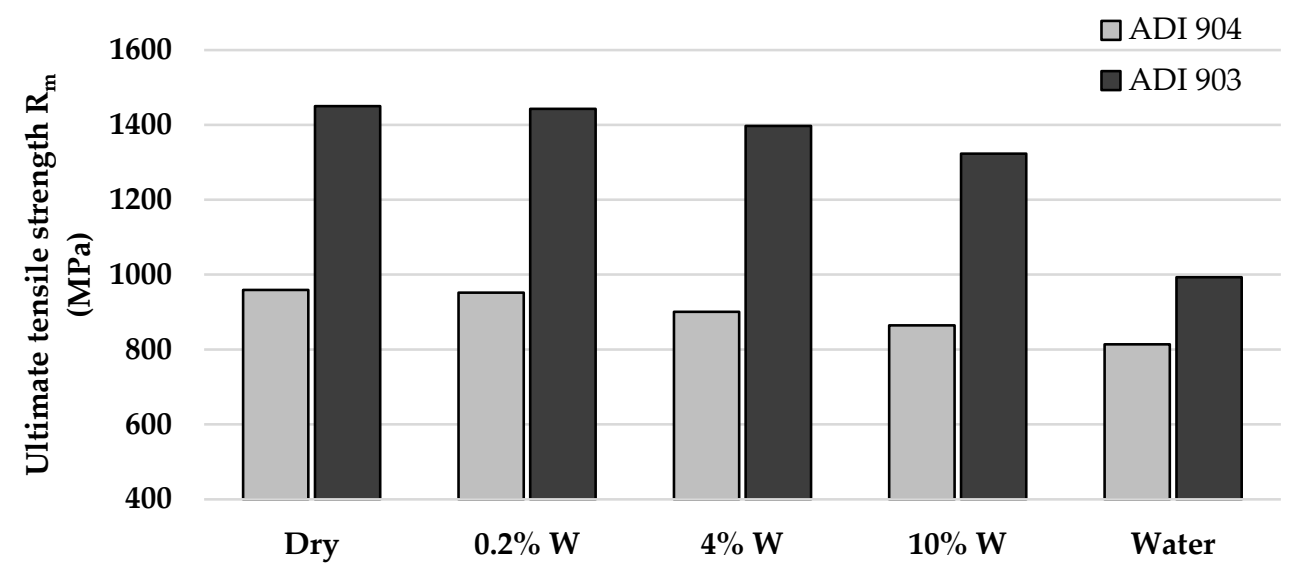

Figure 5. Ultimate tensile strength of ADI material in dry and in environments containing different water concentrations. 


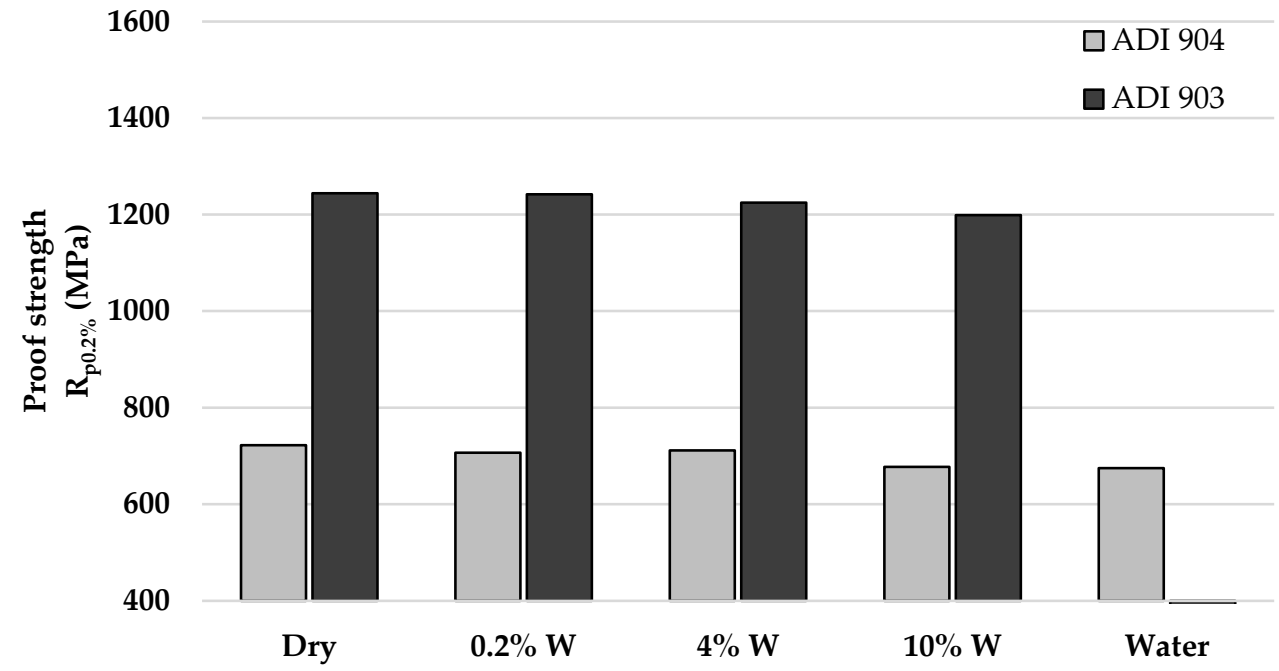

Figure 6. Proof strength of ADI material in dry and in environments containing different water concentrations.

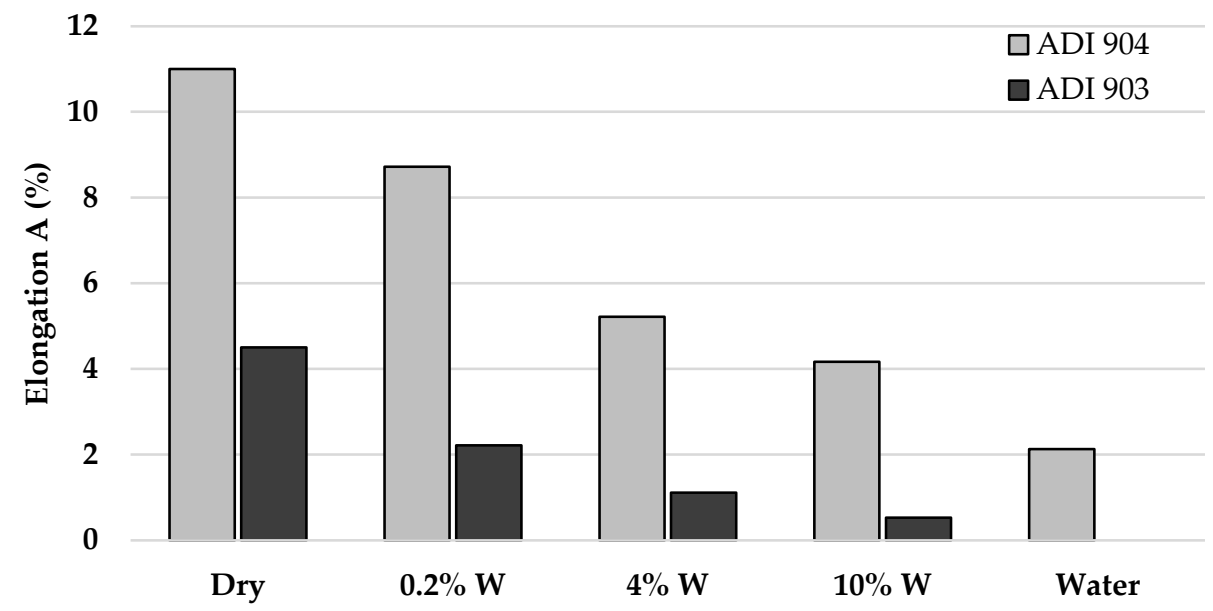

Figure 7. Elongation of ADI material in dry and different water concentrations environments.

Table 3. Ultimate tensile strength, standard deviation, and $p$-values of ADI materials in dry and in environments containing different water concentrations.

\begin{tabular}{|c|c|c|c|c|}
\hline Material & Environment & $\begin{array}{l}\text { Ultimate Tensile Strength } \\
\text { (UTS) } R_{m}(\mathrm{MPa})\end{array}$ & $\begin{array}{c}\text { Standard Deviation } \\
(\mathrm{MPa})\end{array}$ & $p$-Values \\
\hline \multirow{5}{*}{ ADI 904} & Dry & 959 & 15 & - \\
\hline & $0.2 \%$ Water & 952 & 14 & 0.6422 \\
\hline & 4\% Water & 901 & 7 & 0.0078 * \\
\hline & $10 \%$ Water & 864 & 23 & $0.0081 *$ \\
\hline & Water & 814 & 6 & $0.0002 *$ \\
\hline \multirow{5}{*}{ ADI 903} & Dry & 1450 & 3 & - \\
\hline & $0.2 \%$ Water & 1443 & 5 & 0.1144 \\
\hline & 4\% Water & 1397 & 12 & 0.0040 * \\
\hline & $10 \%$ Water & 1324 & 25 & 0.0020 * \\
\hline & Water & 993 & 60 & 0.0004 * \\
\hline
\end{tabular}

${ }^{*} p<0.05$ denotes a statistically significant difference in relation to dry environment. 
Table 4. Proof strength, standard deviation, and $p$-values of ADI materials in dry and different water concentrations environments.

\begin{tabular}{|c|c|c|c|c|}
\hline Material & Environment & $\begin{array}{c}\text { Proof Strength } \\
\text { (PS) } R_{\mathrm{p} 0.2 \%}(\mathrm{MPa})\end{array}$ & $\begin{array}{c}\text { Standard Deviation } \\
(\mathbf{M P a})\end{array}$ & $p$-Values \\
\hline \multirow{5}{*}{ ADI 904} & Dry & 722 & 13 & - \\
\hline & $0.2 \%$ Water & 707 & 12 & 0.2706 \\
\hline & 4\% Water & 711 & 15 & 0.4676 \\
\hline & $10 \%$ Water & 678 & 13 & 0.0248 * \\
\hline & Water & 675 & 6 & 0.0083 * \\
\hline \multirow{5}{*}{ ADI 903} & Dry & 1244 & 49 & - \\
\hline & $0.2 \%$ Water & 1242 & 12 & 0.9844 \\
\hline & 4\% Water & 1225 & 29 & 0.6488 \\
\hline & $10 \%$ Water & 1199 & 28 & 0.3165 \\
\hline & Water & - & - & $3 \times 10^{-06 *}$ \\
\hline
\end{tabular}

${ }^{*} p<0.05$ denotes a statistically significant difference in relation to dry environment.

The representative stress-strain curves for each testing conditions are given in Figure 4. All specimens exhibited identical trend, that is the water environment curves coincide with that of the dry condition up to the point of premature final rupture. The ADI 903 has higher strength with lower elongation due to austempering on higher temperature of $400{ }^{\circ} \mathrm{C}$ and its finer ausferritic microstructure, which is maintained in all tested conditions. The rapture occurs in plastic deformation region of all specimens, except in the case of ADI 903 tested in water which fractures in elastic region.

A column chart presenting ultimate tensile strength (UTS) in various exposure conditions is shown in Figure 5. It is clear that the results show there is clear tendency of UTS to decrease as the water content is increased in relation to the sample tested in dry condition. Furthermore, $0.2 \%$ of water content in the environment also does not cause a statistically significant decrease for both tested materials (Table 3). The maximum reduction in the UTS was obtained for ADI 903 in water (46\%), while the reduction for ADI 904 was $17.8 \%$, both in relation to the UTS obtained in dry condition.

Table 5. Elongation, standard deviation, and $p$-values of ADI materials in dry and different water concentrations environments.

\begin{tabular}{|c|c|c|c|c|}
\hline Material & Environment & $\begin{array}{c}\text { Elongation } \\
\text { A (\%) }\end{array}$ & $\begin{array}{c}\text { Standard Deviation } \\
(\%)\end{array}$ & $p$-Values \\
\hline \multirow{5}{*}{ ADI 904} & Dry & 11.5 & 0.5 & - \\
\hline & $0.2 \%$ Water & 8.7 & 1.6 & 0.0777 \\
\hline & $4 \%$ Water & 5.2 & 0.8 & $0.0007^{*}$ \\
\hline & $10 \%$ Water & 4.2 & 0.4 & $0.0001 *$ \\
\hline & Water & 2.1 & 0.2 & $2 \times 10^{-5 *}$ \\
\hline \multirow{5}{*}{ ADI 903} & Dry & 4.5 & 0.4 & - \\
\hline & $0.2 \%$ Water & 2.2 & 0.1 & 0.0015 \\
\hline & $4 \%$ Water & 1.1 & 0.3 & 0.0006 \\
\hline & $10 \%$ Water & 0.5 & 0.2 & 0.0003 \\
\hline & Water & - & - & $9 \times 10^{-5 *}$ \\
\hline
\end{tabular}

The results of proof strength (PS) are shown in Figure 6 and Table 4. The results show a slight tendency to decrease in relation to the sample tested on dry, except for sample ADI 903 tested in water where fracture occurs suddenly at the UTS, and no PS could be determined. Standard deviations and $P$ values are shown in Table 4 . Statistically significant difference in relation to testing of ADI 904 in dry condition was obtained in specimens tested in environments containing $10 \%$ and $100 \%$ water, while for ADI 903, a statistically significant difference was only related to specimens tested in water environment.

The results of elongation (A) are shown in Figure 7. The column chart clearly indicates the tendency towards the decrease in elongation as the water content is higher in the tensile 
testing environment, compared to the sample tested dry. The value for ADI 903W was not determined as the fracture was without measurable plastic deformation. Standard deviations and $P$ values are shown in Table 5. All specimens (ADI 904 and ADI 903) tested in water environments exhibited statistically significant differences between obtained elongations, versus the elongation obtained in dry condition, the only exception being ADI 904 tested in 0.2 vol. \% water environment.

\subsection{Fracture Behavior}

The macro appearance of the fracture surfaces of tensile specimens tested in dry condition, water (as the most extreme condition for the embrittlement as shown by tensile testing results), and 0.2 vol.\% water concentration in ethyl alcohol (as lowest water concentration and thus the mildest condition for embrittlement), are represented in Figure 8.
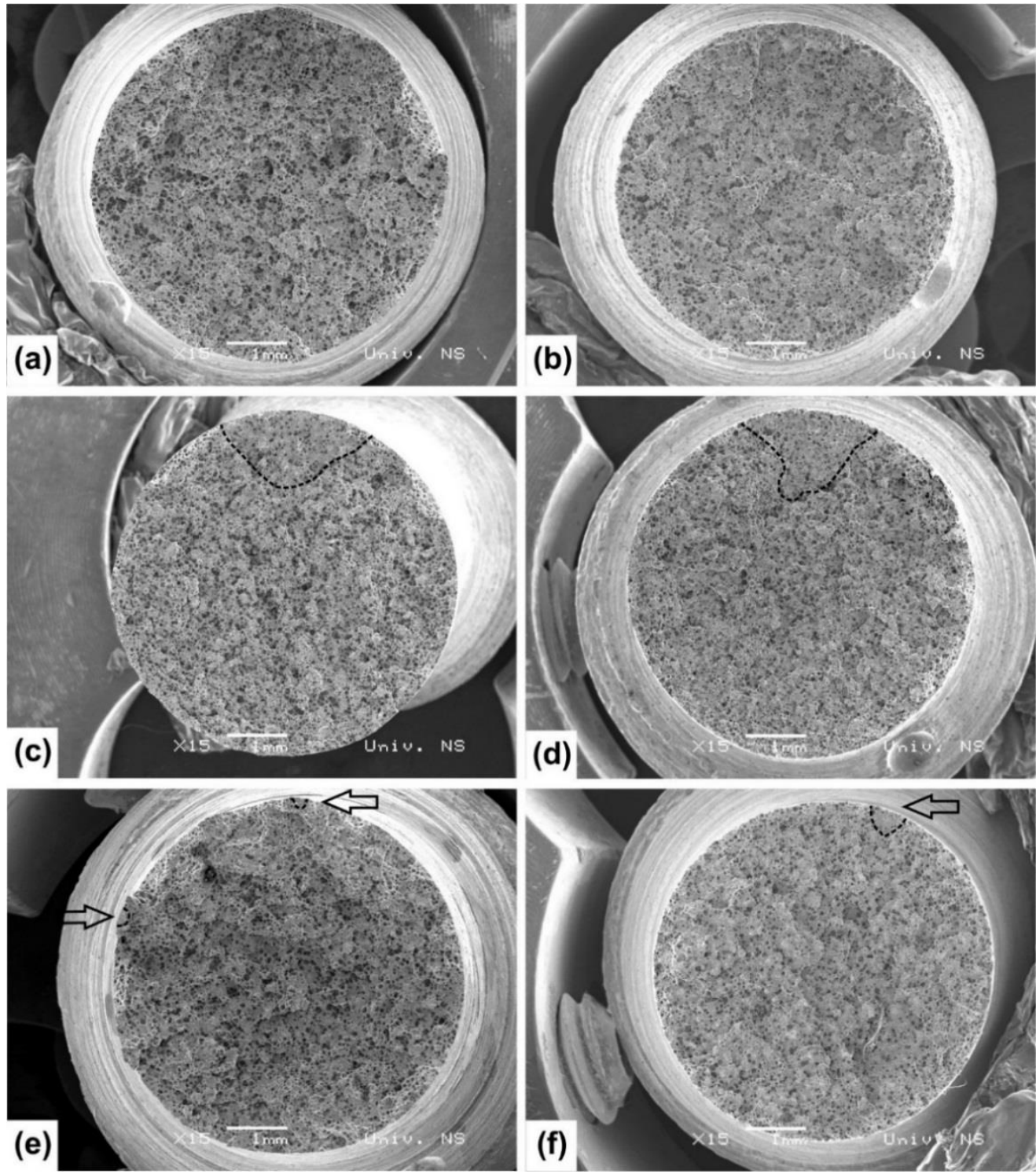

Figure 8. Macro appearance of fracture surface: (a) ADI 903 in dry condition; (b) ADI 904 in dry condition; (c) ADI 903 in water; (d) ADI 904 in water; (e) ADI 903 in 0.2 vol.\% water; (f) ADI 904 in 0.2 vol. $\%$ water (the embrittlement zone is enclosed by dashed line and indicated by arrow).

Both ADI materials (Figure 8a,b) exhibit the whole fracture surface comprised of uniformly distributed dimples and graphite nodules in dry condition. On the other hand, the fracture surfaces of samples tested in different water concentrations, expose two separate 
fracture zones: A fracture zone that is flat and bright near the specimen surface, and a larger dimpled zone in the rest of the fracture surface. These two zones are easily observed for the testing in pure water (enclosed by dashed line in Figure 8c,d). Furthermore, the water embrittled zone area is decreasing with the reduction of water concentration in the environment. The two distinctive fracture zones are also present in specimens tested in 0.2 vol.\% water concentration (enclosed by dashed line and pointed by an arrow in Figure $8 \mathrm{e}, \mathrm{f})$. These fracture features are difficult to be observed visually. While embrittlement of the ADI 904 in 0.2 vol.\% water could be visually observed as a small bright zone, the embrittlement zones of the ADI 903 was determined only after the high magnification examination by SEM.

The fracture mode of dry samples is shown in Figure 9, while the characteristic fracture surfaces outside the embrittlement zone when tested in water are illustrated in Figure 10. As it can be observed, there is no significant difference between the fracture mode of samples tested in dry condition, and the fracture mode outside the embrittlement zone. In all aforementioned cases, the fracture mode has an appearance of a mix mode fracture: Ductile dimpled fracture and dispersed cleavage facets associated with brittle fracture. This mixed mechanism of fracture is refereed as quasi-cleavage [30].

The detailed examination of the embrittlement zone is presented in Figures 11-16, for ADI 903 and ADI 904 tested in water and 0.2 vol.\% water concentration in ethyl alcohol. It can be seen that the embrittlement zone, which appears flat and bright visually, exhibits transgranular brittle fracture.
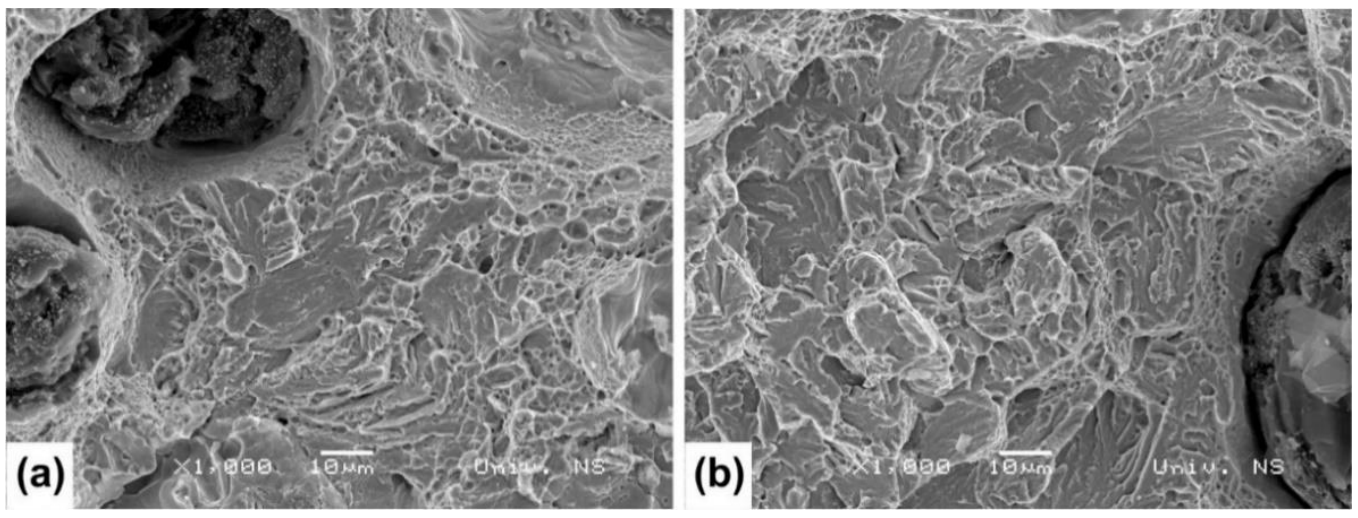

Figure 9. Fracture mode of the ADI materials tested in dry condition: (a) ADI 903; (b) ADI 904.
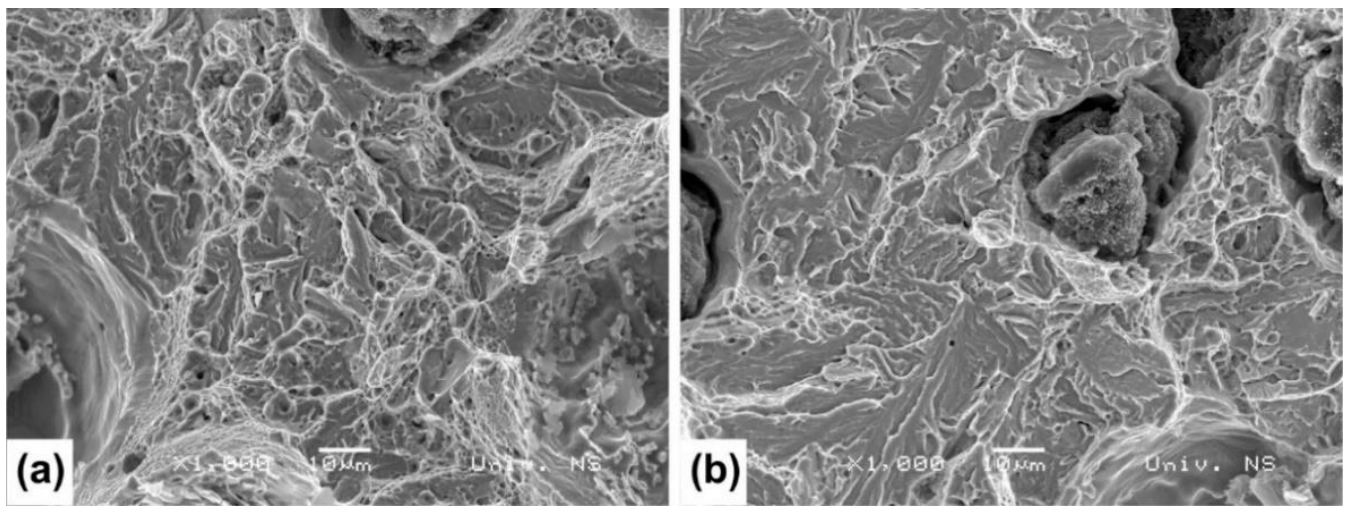

Figure 10. Fracture mode outside the embrittlement zone of the ADI materials tested in water: (a) ADI 903; (b) ADI 904.

The fracture surface does not have typical brittle (cleavage) morphology, but it consisted of randomly oriented striation lines. This could be related to the random orientation of ausferritic ferrite and retained austenite plates seen in the microstructure (Figure 2). The 
brittle fracture appearance could be further associated with flat, narrow, serrated facets of striations lines in the form of steps and tear ridges. A similar fracture mode in the embrittlement zone is observed for all samples tested in contact with water, suggesting a common cause of crack formation and growth mechanism.

The ADI 903 tested in water the embrittlement zone has a semicircular appearance with radius of around $1.5 \mathrm{~mm}$ (Figure 11a). The zone starts from the free surface of sample. However, the point of origin could not be distinguished between machined surface and nodule pits. Furthermore, a small separation between graphite nodules and nodule pit walls could be observed, suggesting that water penetrates easily under the machined surface to the nodule pits during tension testing (Figure 11b). The striation lines are very fine with multiple serrated faces, steps, and tear ridges (Figure 11c,d).
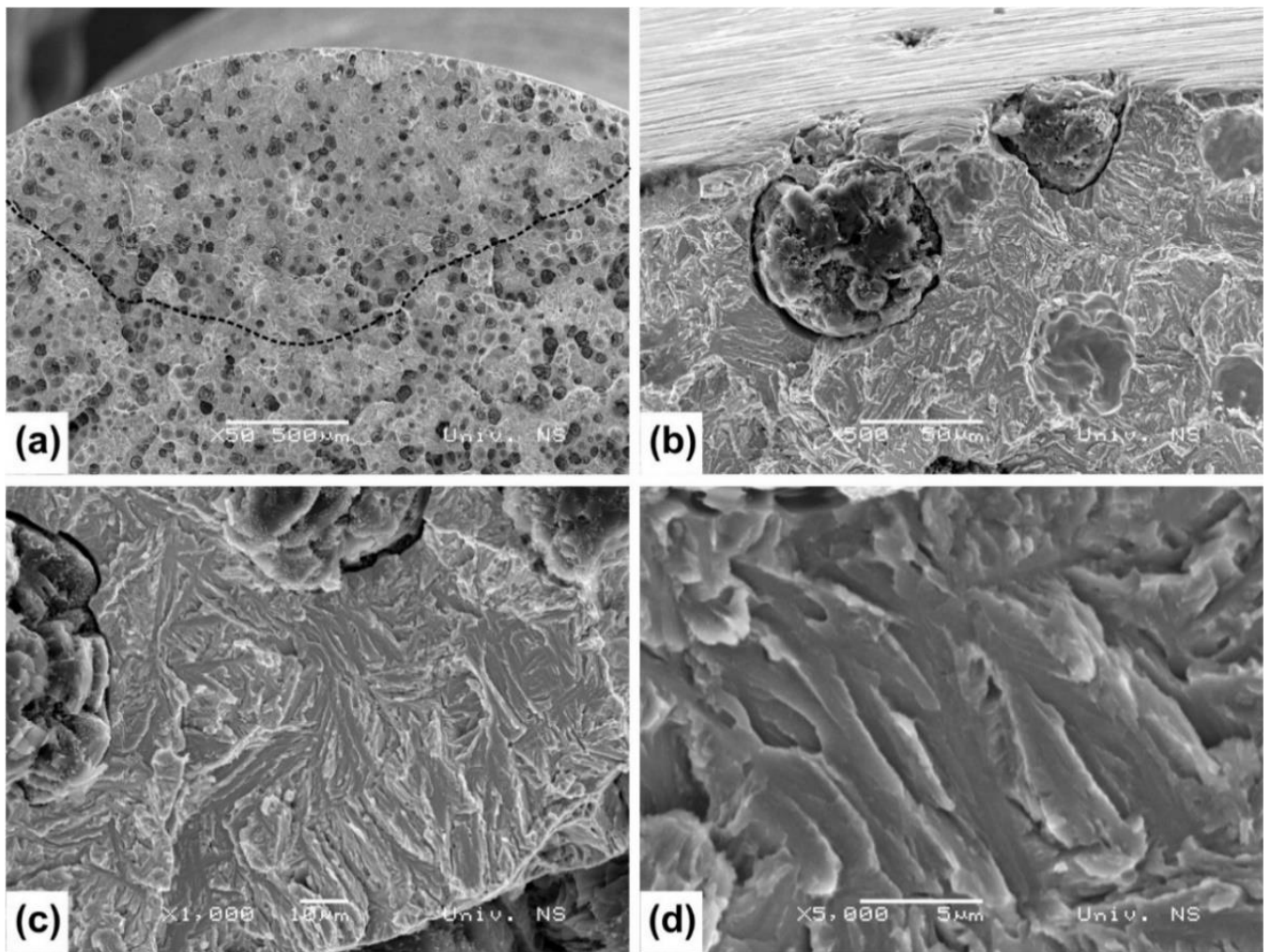

Figure 11. Fracture mode of the embrittlement zone of the ADI 903 tested in water: (a) the embrittlement zone enclosed by dashed line; $(\mathbf{b}-\mathbf{d})$ striation lines in the embrittlement zone.

The embrittlement zone of the ADI 903 tested 0.2 vol. \% water could not be observed visually, however through a thorough inspection by SEM, two small embrittlement zones could be identified (Figure 12). The zones have an irregular semicircle appearance with a radius of around $0.1 \mathrm{~mm}$. Inside the embrittlement zone, like in previous cases, a striation appearance of fracture surface is present (Figure 12b,d). However, the embrittlement zone is enclosed with material exhibiting mixed mode fracture. The ADI 904 tested in water (Figure 13) exhibits similar fracture appearance as ADI 903. The fracture surface consisted of the embrittlement zone and the quasi-cleavage zone. The approximate depth of the embrittlement zone is about $1.5 \mathrm{~mm}$ (Figure 13a). The striation lines in the embrittlement zone are coarser with wider serrated facets (Figure 13b-d) compared to the ADI 903 (Figure 11d). Furthermore, the careful examination of the embrittlement zone revealed a presence of small, isolated brittle facets near sample free surface, indicated by arrows in Figure 14a. The small brittle areas have a fan-shaped form and exhibit a typical brittle fracture appearance with bright crystalline cleavage facets and river pattern strips (Figure 14b). 

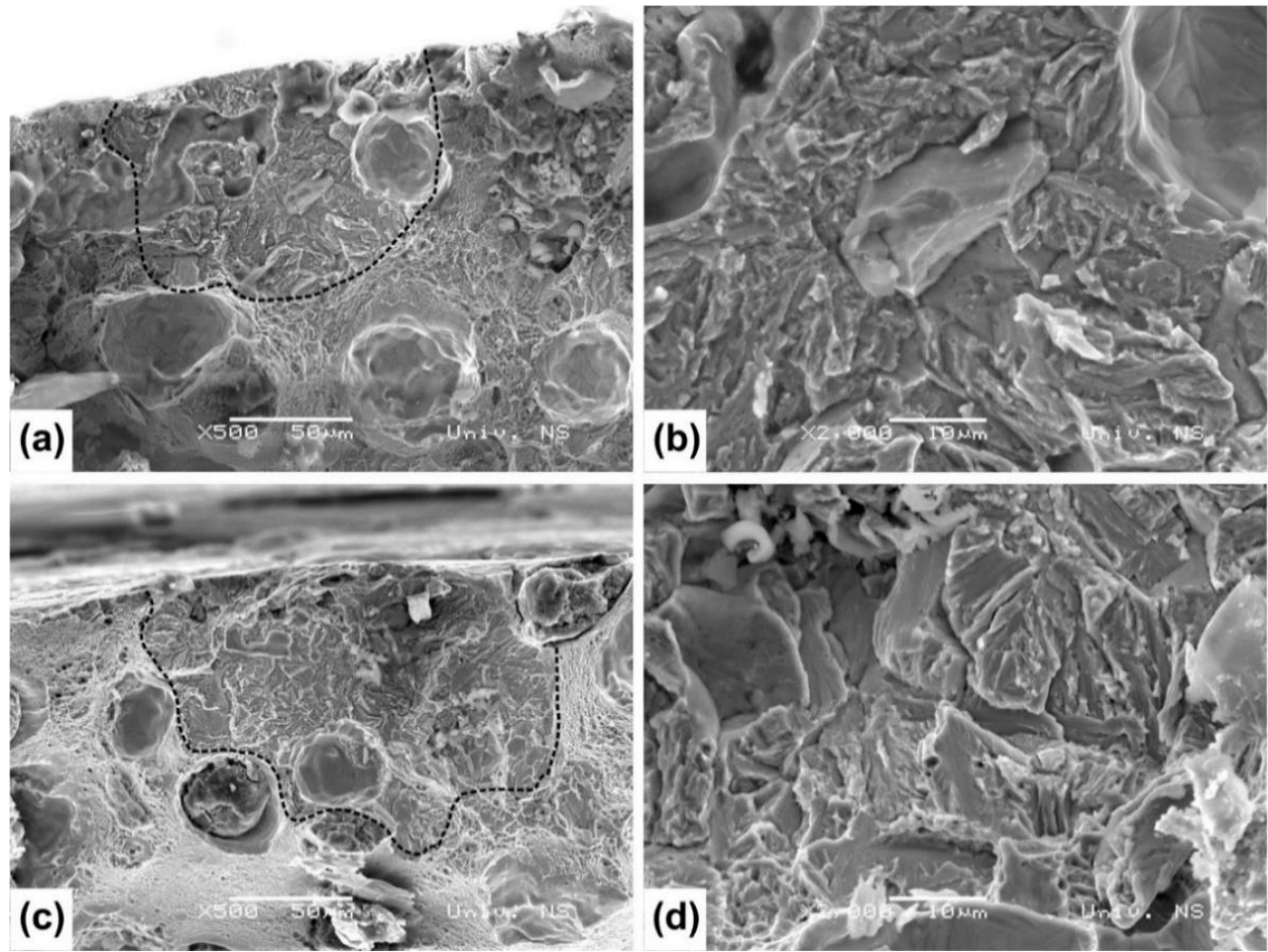

Figure 12. Fracture mode of the embrittlement zone of the ADI 903 tested in 0.2 vol.\% water: $(\mathbf{a}, \mathbf{c})$ the embrittlement zones enclosed by dashed line; (b,d) higher magnification of the corresponding embrittlement zones, respectively.

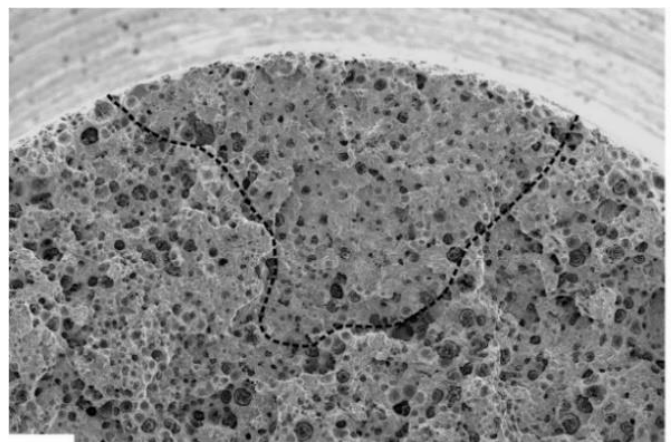

(a)
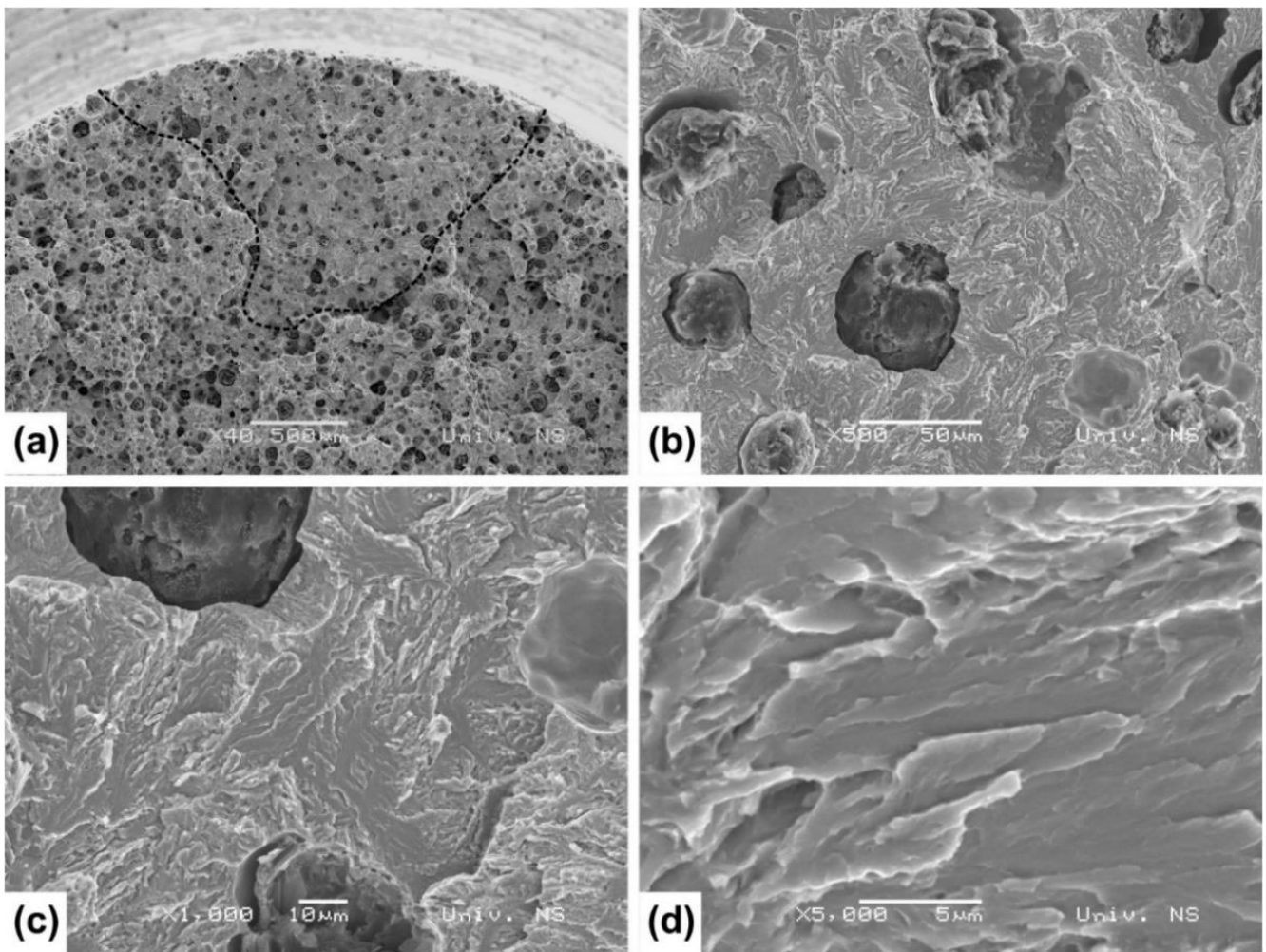

Figure 13. Fracture mode of the embrittlement zone of the ADI 904 tested in water: (a) the embrittlement zone enclosed by dashed line; $(\mathbf{b}-\mathbf{d})$ striation lines in the embrittlement zone. 

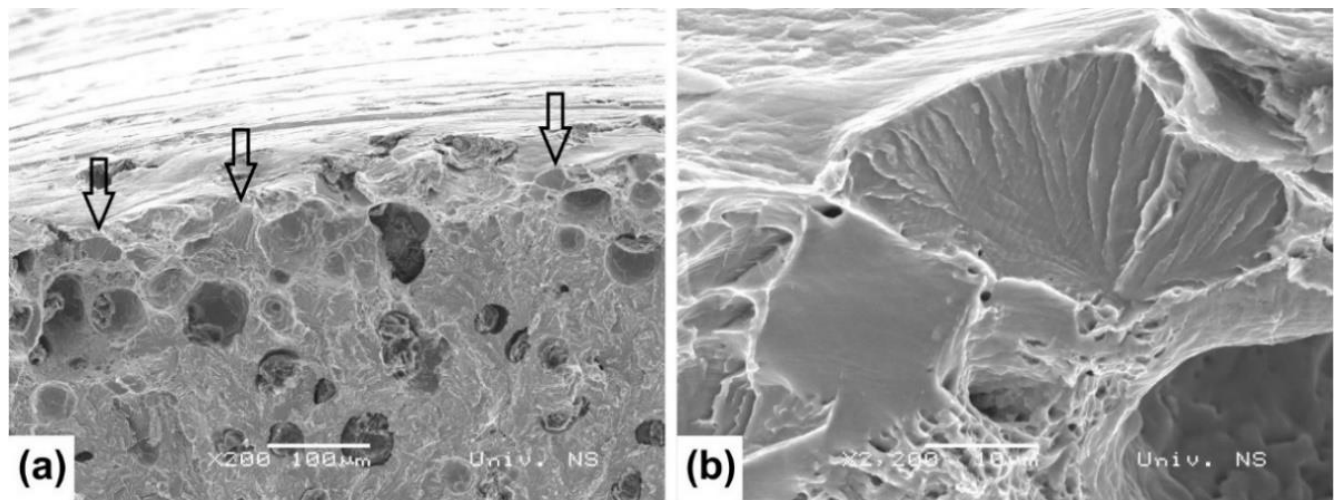

Figure 14. Surface detail of embrittlement zone of the ADI 904 tested in water: (a) fan-shaped, brittle facets indicated by arrows; (b) higher magnification of the fan-shaped brittle facet.

The embrittlement zone of the ADI 904 tested in 0.2 vol.\% water is considerably smaller compered to testing in water and has a more wedge shape appearance (Figure 15a), compared to more semi-circle appearances in previous specimens. The depth of this zone is around $0.5 \mathrm{~mm}$, with similar width at the free surface of the specimen. Furthermore, the presence of small brittle facets near sample free surface is observed, as well, indicated by arrows in Figure 15a,b. In Figure 15c, a transition line between the embrittlement and non-embrittlement zone is presented. The transition from striations lines fracture to the quasi-cleavage with pronounced dimpled (ductile) component can be seen.
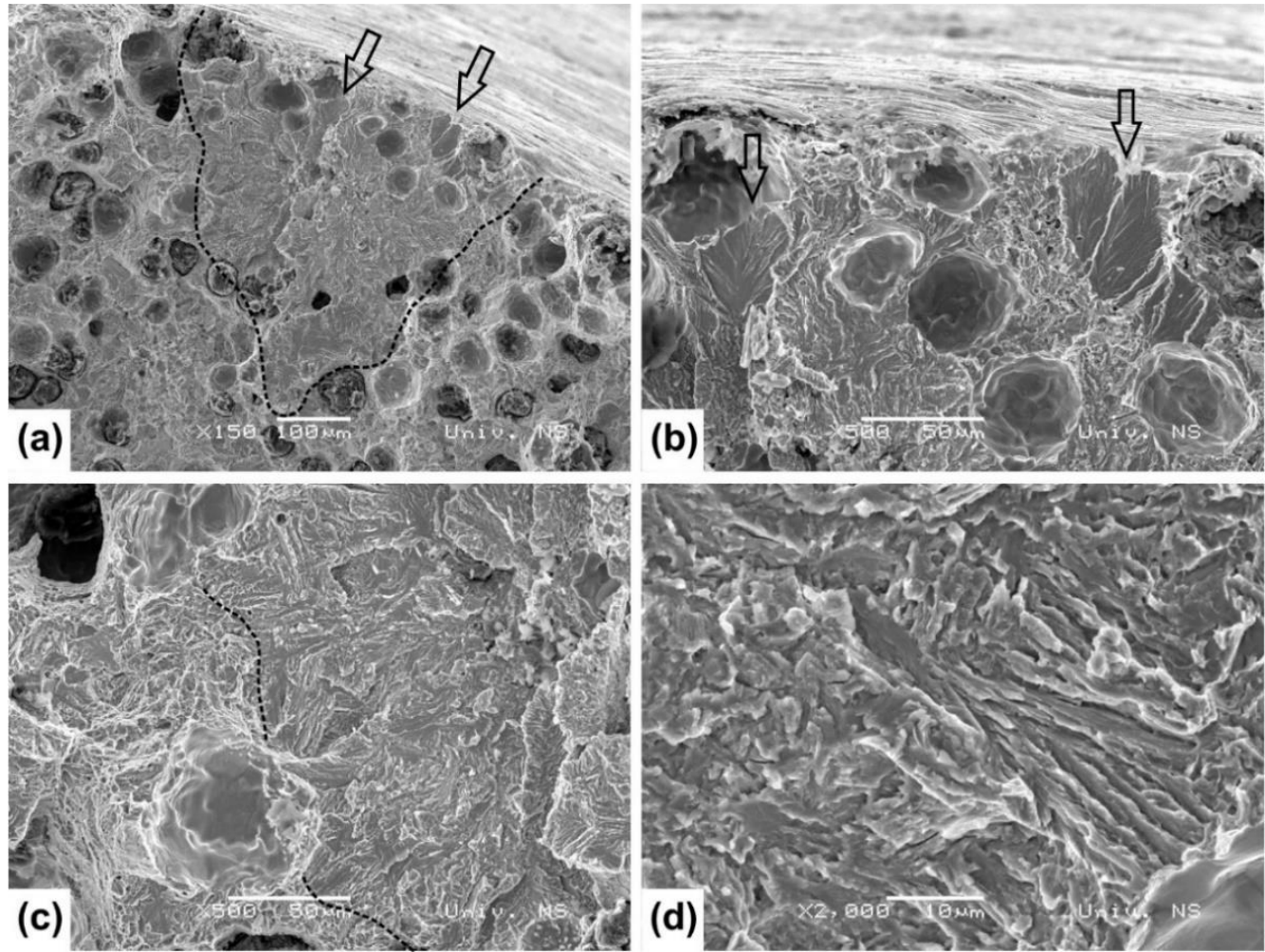

Figure 15. Fracture mode of embrittlement zone of the ADI 904 tested in 0.2 vol.\% water: (a) the embrittlement zone enclosed by dashed line; (b) fan-shaped, brittle facets indicated by arrow; (c) transition from striations lines to the quasi-cleavage fracture; (d) striation lines.

Besides fan-shaped small brittle facets in the embrittlement zone, the isolated brittle facets are also observed in the other parts of specimen, indicated by arrows in Figure 16a. The isolated brittle facets also have a fan-shape form with crystalline cleavage facets and 
river pattern strips. They are located at the free surface of sample; enclosed in the region of mixed ductile (dimpled) and quasi-cleavage fracture mode, Figure $16 \mathrm{~b}$.
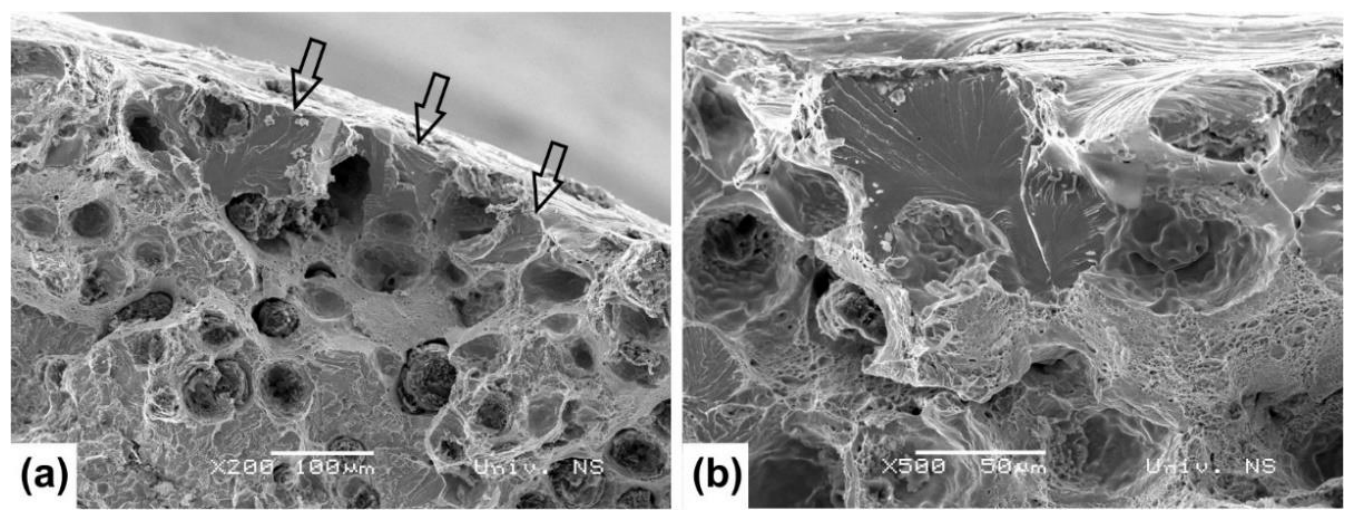

Figure 16. Surface detail outside of the embrittlement zone of the ADI 904 tested in 0.2 vol.\% water: (a) fan-shaped, brittle facets indicated by arrows; (b) a fan-shaped brittle facet.

\section{Discussion}

In this work, two different ADI materials with different microstructures and mechanical properties were obtained by the heat treatment of the standard nodular cast iron. The mechanical properties of both ADI materials were lower when tested in water as opposed to dry testing. The decline in mechanical properties, referring to the ultimate tensile strength (UTS), proof strength (PS), and elongation (A) was increasing with increasing the water concentration in environment.

The elongation was the most sensitive tensile property to the increase of water concentration in the testing environment. Even small concentrations of water $(0.2 \mathrm{vol} . \%)$ create small cracks, as shown by the results of fracture surfaces examination, while higher concentrations induce larger cracks. The formed cracks limit the plastic deformation of the material, even leading to fracture without measurable plastic deformation in case of ADI 903 in a 100 vol.\% water environment. This sudden fracture of the ADI 903, and its higher relative elongation reduction compared to the ADI 904, could be correlated to the microstructure produced at the lower austempering temperature of $300{ }^{\circ} \mathrm{C}$, which due to its fine acicular (needle-like) ausferrite morphology has higher strength, however with lower ductility [8-10]. Thus, it is more susceptible to fast fracture and crack propagation when the crack is formed. Furthermore, higher PS of ADI 903 accommodate for sufficient elastic strain, which is needed to reduce the energy barrier for diffusion of hydrogen atoms, while the relatively high stresses in the case of testing in $100 \mathrm{vol} . \%$ of water promotes fast crack formation and propagation $[19,20]$. On the other hand, more ductile ausferritic matrix of the ADI 904 with plate-like morphology was capable to contain fast propagation of the embrittlement crack, thus retaining some ductility $(\mathrm{A}=2.1 \%)$ even when tested in 100 vol. $\%$ water.

The lower PS, higher ductility, and microstructure with higher austenite content in ADI 904, ease the formation of the larger embrittlement zone. As stated by Komatsu et al. [19], for the crack formation, it is required to have: A sufficient plastic strain for formation of localized corrosion cells; a sufficient elastic strain to increase the lattice spacing to ease diffusion of hydrogen atoms; and a large enough stress to form surface cracks. All these conditions are exhibited by the ADI 904, leading to the larger observed embrittlement zones. Furthermore, the embrittlement zone in ADI 904 has a more wedge shape appearance compared to a semi-circle appearance in ADI 903. Furthermore, in ADI 904, a presence of small brittle facets near sample free surface could be observed. It could be assumed that the formation of brittle facets could be associated with formation of martensite, as during plastic deformation of the ADI 904, due to a higher content of retained austenite, which is less stable (lower carbon content) when produced at higher austempering temperatures $[4,9,10]$, 
a martensite could be formed by SITRAM/SATRAM effect (strain-induced or stress-assisted phase transformation of retained austenite into martensite), which is supported by the literature $[4,15]$. Thus, those brittle facets additionally promote formation of relatively larger embrittlement crack zones in case of the ADI 904.

The ADI 903 maintains higher values of the UTS and PS in all tested environments due to its fine acicular ausferrite morphology, compared to a plate-like ausferrite morphology of the ADI 904 [8-10]. Sudden fracture occurred in the ADI 903 only when tested in a water environment. However, the overall relative decrease of UTS in water environments is similar in both ADI materials. This kind of behavior could be associated with the smaller size of the embrittlement zone in ADI 903 and to the matrix toughness, which is higher in ADI 904, thus resulting in similar relative reduction of the UTS in both materials. It should be noted that although the statistical analysis did not give a significant difference in the UTS in ADI 903 and ADI 904 tested in of 0.2 vol.\% water environment, the formation of a small brittle zone is observed in both materials. While this zone is diminutive for the ADI 903, it was more pronounced in the ADI 904. However, in both cases, even as materials experience embrittlement in contact with the slightest water concentrations, it was insufficient to form critical size embrittlement crack zone, which would cause rapid fracture propagation, and thus influence the significant reduction in the UTS compared to materials tested in dry conditions.

The proof strength is statistically least influenced by water concentration. This corresponds to literature findings $[19,20,29]$ that it is necessary to reach a certain level of applied elastic stress and plastic strain, which will allow sufficient hydrogen chemisorption and thus formation and propagation of the crack. The statistically significant results were obtained only at high water concentrations of 10 and 100 vol.\% for ADI 904, and at 100 vol.\% for ADI 903 (sudden fracture of the ADI 903). The difference in critical water concentration on embrittlement between the ADI 904 (more susceptible) and ADI 903 (less susceptible) could be attributed to higher levels of stress needed for plastic deformation of the ADI 903.

The water embrittled zone for both ADI materials have similar fracture appearance, and the embrittlement zone was observed for all water concentrations, even in the case of the lowest amounts of 0.2 vol.\%. However, the embrittlement fracture surface does not have typical appearance of the ADI material brittle fracture, which occurs at low temperatures or after prolonged austempering, that is, there is no wide cleavage facets and clear river patterns [8,29-32]. The embrittlement zone fracture morphology is in the form of narrower serrated facets, forming shallow steps and tear ridges, which are repeatedly stretching from free sample surface or from graphite spheres. Furthermore, in case of the ADI 904, a formation of small brittle facets near sample free surface is observed, which could enhance crack formation. The origin of striations lines could not be distinguished between machined surface and nodule pits. However, it is safe to assume that water could penetrate into graphite nodule pits, as small separation between nodule and matrix was observed, and there are exposed graphite nodules on machined surface. Water penetration increases contact area, and hence the possibility of the embrittlement crack zone formation. The repeating appearance of the brittle zone morphology may be attributed to the cyclic propagation of crack due to the cyclic nature of atomic hydrogen chemisorption into the narrow region under the specimen surface under strained conditions, where local microembrittlement may be induced, followed by brittle micro-fracture and formation of the new free surface where chemisorption might start again $[19,26,29]$. The cyclic embrittlement nature is further supported by the large size of the embrittlement zone, since hydrogen diffusion over few millimeters of embrittlement zone in few minutes (the time of test) would indicate an anomalous hydrogen diffusion coefficient. Thus, classical hydrogen diffusion mechanism of embrittlement [33] might not be applicable in the case of ADI material embrittlement in water.

The results in terms of tensile properties and fracture surfaces show that hydrogen chemisorption requires critical stress and water concentration which form a hydrogen embrittlement zone. The crack expands and affects primarily the elongation and UTS, 
while the PS remains less affected. Although a certain combination of water content in the environment and stress must be achieved for the mechanical properties to be affected, the examination of fracture surfaces showed that a small embrittlement crack is formed even when testing was done in the lowest water concentration environment.

\section{Conclusions}

In accordance with the results presented in this study, and within the limitations set in the experimental part, the following set of conclusions can be drawn:

- The water environment has a clear harmful influence on the mechanical properties of ADI materials. As the water content in the environment increases, tensile properties decrease.

- The highest deterioration was established in the elongation, followed by the ultimate tensile strength, while the proof strength was affected least.

- Even the smallest concentration of water affects the fracture morphology by forming the embrittlement zone. However, in a 0.2 vol.\% water environment, a crack could not propagate unstably and thus embrittlement does not have a statistically significant effect on tensile properties.

- In all samples tested at different water concentrations, the crack propagation starts from the embrittlement zone, which origins from free sample surface.

- The formation of the embrittlement zone acts as a primary weak spot for the crack nucleation and subsequent fracture. The origin of this phenomenon is the chemisorption of hydrogen atoms from water into the material surface.

Author Contributions: Conceptualization, D.R. and L.S.; formal analysis, P.J., D.R., S.B., M.D., O.E.C., and J.G.N.; investigation, P.J., D.R., and M.D.; methodology, P.J., D.R., O.E.C., and S.B.; validation, D.R., J.G.N., and S.B.; resources, D.R.; data curation, P.J., D.R., and M.D.; writing-original draft preparation, P.J., D.R., S.B., and L.S.; writing-review and editing, P.J., D.R., and S.B.; visualization, D.R. and P.J.; supervision, O.E.C. and L.S. All authors have read and agreed to the published version of the manuscript.

Funding: This research was funded by Ministry of Education, Science and Technological Development of the Republic of Serbia, grant number: 451-03-68/2020-14/200156, and 451-03-68/2020$14 / 200108$.

Institutional Review Board Statement: Not applicable.

Informed Consent Statement: Not applicable.

Data Availability Statement: The data presented in this study are available on request from the corresponding author. The data are not publicly available due to intellectual rights concerns.

Acknowledgments: This paper has been supported by the Ministry of Education, Science and Technological Development of the Republic of Serbia through the project no. 451-03-68/2020-14/200156: "Innovative scientific and artistic research from the Faculty of Technical Sciences, Novi Sad, Serbia, activity domain", and the project no. 451-03-68/2020-14/200108: "Innovative scientific and artistic research from the Faculty of Mechanical and Civil Engineering in Kraljevo, University of Kragujevac, Serbia, activity domain".

Conflicts of Interest: The authors declare no conflict of interest. The funders had no role in the design of the study; in the collection, analyses, or interpretation of data; in the writing of the manuscript, or in the decision to publish the results.

\section{References}

1. Tanaka, Y.; Kage, H. Development and application of austempered spheroidal graphite cast iron. Mater. Trans. JIM 1992, 33, 543-557. [CrossRef]

2. Balos, S.; Radisavljevic, I.; Rajnovic, D.; Janjatovic, P.; Dramicanin, M.; Eric-Cekic, O.; Sidjanin, L. Ballistic Behaviour of Austempered Compacted Graphite Iron Perforated Plates. Def. Sci. J. 2019, 69, 571-576. [CrossRef]

3. ASM International. ASM Handbook, Fatigue and Fracture; American Society for Materials: Novelty, OH, USA, 1996; Volume 19, p. 665. 
4. Balos, S.; Rajnovic, D.; Dramicanin, M.; Labus, D.; Eric-Cekic, O.; Grbovic-Novakovic, J.; Sidjanin, L. Abrasive wear behaviour of ADI material with various retained austenite content. Int. J. Cast Met. Res. 2016, 29, 187-193. [CrossRef]

5. Sidjanin, L.; Smallman, E.R.; Young, J.M. Electron Microstructure and Mechanical Properties of Silicon and Aluminium Ductile Irons. Acta Metall. Mater. 1994, 42, 3149-3156. [CrossRef]

6. Eric Cekic, O.; Dojcinovic, M.; Rajnovic, D.; Sidjanin, L.; Balos, S. Microstructure and cavitation behaviour of alloyed austempered ductile irons. Int. J. Cast Met. Res. 2018, 31, 279-287. [CrossRef]

7. Eric Cekic, O.; Sidjanin, L.; Rajnovic, D.; Balos, S. The Austempering Kinetics of Cu-Ni Alloyed Austempered Ductile Iron. Met. Mater. Int. 2014, 20, 1131-1138. [CrossRef]

8. Eric, O.; Rajnović, D.; Zec, S.; Sidjanin, L.; Jovanović, T. Microstructure and fracture of alloyed austempered ductile iron. Mater. Charact. 2006, 57, 211-217. [CrossRef]

9. Sidjanin, L.; Rajnovic, D.; Eric, O.; Smallman, R.E. Austempering study of unalloyed and alloyed ductile irons. Mater. Sci. Technol. 2010, 26, 567-571. [CrossRef]

10. Harding, R.A. The production, properties and automotive applications for austempered ductile iron. Kovove Mater. 2007, 45, 1-16.

11. Eric, O.; Rajnovic, D.; Sidjanin, L.; Zec, S.; Jovanovic, T. An austempering study of ductile iron alloyed with copper. J. Serb. Chem. Soc. 2005, 70, 1015-1022. [CrossRef]

12. Dojcinovica, M.; Eric, O.; Rajnovic, D.; Sidjanin, L.; Balos, S. Effect of austempering temperature on cavitation behaviour of unalloyed ADI material. Mater. Charact. 2013, 82, 66-72. [CrossRef]

13. Goergen, F.; Mevissen, D.; Masaggia, S.; Veneri, E.; Brimmers, J.; Brecher, C. Contact Fatigue Strength of Austempered Ductile Iron (ADI) in Gear Applications. Metals 2020, 10, 1147. [CrossRef]

14. Rimmer, A. ADI is Growing. Mater. World 1997, 5, 252-255.

15. Balos, S.; Radisavljevic, I.; Rajnovic, D.; Dramicanin, M.; Tabakovic, S.; Eric-Cekic, O.; Sidjanin, L. Geometry, mechanical and ballistic properties of ADI material perforated plates. Mater. Des. 2015, 83, 66-74. [CrossRef]

16. Cai, Q.Z.; Wei, B.K.; Tanaka, Y. Fatigue Properties of Austempered Ductile Iron (ADI) in Water Environment. Acta Metall. Sin. 2004, 17, 122-130.

17. Martinez, R.A.; Simison, S.N.; Boeri, R.E. Environmentally Assisted Embrittlement of ADI—Current Understanding, 2002 World Conference on ADI, Louisville, KY, USA, 26-27 September 2002; American Foundry Society: Schaumburg, IL, USA, 2002.

18. Komatsu, S.; Zhou, C.Q.; Shibutani, S.; Tanaka, Y. Embrittlement Characteristics of Fracture Toughness in Ductile Iron by Contact with Water. Int. J. Cast Metals Res. 1999, 11, 539-544. [CrossRef]

19. Komatsu, S.; Osafune, Y.; Tanaka, Y.; Tanigawa, K.; Shibutani, S.; Kyogoku, H. Influence of water embrittlement effect on mechanical properties of ADI. Int. J. Cast Met. Res. 2003, 16, 209-214. [CrossRef]

20. Martínez, R.A.; Boeri, R.E.; Sikora, J.A. Embrittlement of ADI caused by contact with water and other liquids. Int. J. Cast Met. Res. 2000, 13, 9-15. [CrossRef]

21. Masud, L.; Martínez, R.; Simison, S.; Boeri, R. Embrittlement of austempered ductile iron on contact with water-Testing under applied potential. J. Mater. Sci. 2003, 38, 2971-2977. [CrossRef]

22. Caballero, L.; Elices, M.; Parkins, R.N. Environment-sensitive fracture of austempered ductile iron. Corrosion 2005, 61, 51-57. [CrossRef]

23. Shibutani, S.; Komatsu, S.; Tanaka, Y. Embrittlement of Austempered Spheroidal Graphite Cast Iron by Contact with Water and Resulting Preventing Method. Int. J. Cast Met. Res. 1999, 11, 579-585. [CrossRef]

24. Song, Y.H.; Lui, T.S.; Chen, L.H.; Song, J.M. Effect of nodular graphite on the deterioration of vibration fracture resistance of ferritic cast iron under an aqueous environment. Mater. Trans. 2003, 44, 1461-1468. [CrossRef]

25. Shiraki, N.; Sugiyama, Y.; Imai, T. Effects of water and humidity on fracture toughness of spheroidal graphite cast iron. J. Jpn. Foundry Eng. Soc. 2005, 77, 167-172. [CrossRef]

26. Lynch, S.P. Environmentally assisted cracking: Overview of evidence for an adsorption-induced localised-slip process. Acta Metall. 1988, 36, 2639-2661. [CrossRef]

27. Wang, M.; Akiyama, E.; Tsuzaki, K. Effect of hydrogen on the fracture behavior of high strength steel during slow strain rate test. Corros. Sci. 2007, 49, 4081-4097. [CrossRef]

28. Caldera, M.; Martínez, R.A.; Boeri, R.E.; Sikora, J.A. Evaluation of water embrittlement on 'dual phase' ADI. Fatigue Fract. Eng. Mater. Struct. 2011, 34, 774-781. [CrossRef]

29. Rajnovic, D.; Balos, S.; Sidjanin, L.; Eric Cekic, O.; Grbovic Novakovic, J. Tensile properties of ADI material in water and gaseous environments. Mater. Charact. 2015, 101, 26-33. [CrossRef]

30. Martinez, R.A. Fracture surfaces and the associated failure mechanisms in ductile iron with different matrices and load bearing. Eng. Fract. Mech. 2010, 77, 2749-2762. [CrossRef]

31. Rajnovic, D.; Eric, O.; Sidjanin, L. Transition temperature and fracture mode of as-cast and austempered ductile iron. J. Microsc. 2008, 232, 605-610. [CrossRef]

32. Rajnovic, D.; Eric, O.; Sidjanin, L. The standard processing window of alloyed ADI materials. Kovove Mater. 2012, 50, 199-208. [CrossRef]

33. Li, X.; Ma, X.; Zhang, J.; Akiyama, E.; Wang, Y.; Song, X. Review of Hydrogen Embrittlement in Metals: Hydrogen Diffusion, Hydrogen Characterization, Hydrogen Embrittlement Mechanism and Prevention. Acta Metall. Sin. 2020, 33, 759-773. [CrossRef] 